\title{
Two independent proteomic approaches provide a comprehensive analysis of the synovial fluid proteome response to Autologous Chondrocyte Implantation
}

Charlotte H. Hulme ${ }^{1,2}$, Emma L. Wilson ${ }^{2,3}$, Heidi R. Fuller', Sally Roberts ${ }^{1,2}$, James B. Richardson 1,2, Pete Gallacher ${ }^{1,2}$, Mandy J. Peffers ${ }^{4}$, Sally L. Shirran ${ }^{5}$, Catherine H. Botting ${ }^{5}$ and Karina T. Wright ${ }^{1,2^{*}}$

\begin{abstract}
Background: Autologous chondrocyte implantation (ACI) has a failure rate of approximately $20 \%$, but it is yet to be fully understood why. Biomarkers are needed that can pre-operatively predict in which patients it is likely to fail, so that alternative or individualised therapies can be offered. We previously used label-free quantitation (LF) with a dynamic range compression proteomic approach to assess the synovial fluid (SF) of ACl responders and non-responders. However, we were able to identify only a few differentially abundant proteins at baseline. In the present study, we built upon these previous findings by assessing higher-abundance proteins within this SF, providing a more global proteomic analysis on the basis of which more of the biology underlying ACl success or failure can be understood.

Methods: Isobaric tagging for relative and absolute quantitation (iTRAQ) proteomic analysis was used to assess SF from $\mathrm{ACl}$ responders (mean Lysholm improvement of 33; $n=14$ ) and non-responders (mean Lysholm decrease of 14; $n=13$ ) at the two stages of surgery (cartilage harvest and chondrocyte implantation). Differentially abundant proteins in iTRAQ and combined iTRAQ and LF datasets were investigated using pathway and network analyses.

Results: ITRAQ proteomic analysis confirmed our previous finding that there is a marked proteomic shift in response to cartilage harvest (70 and 54 proteins demonstrating $\geq 2.0$-fold change and $p<0.05$ between stages I and II in responders and non-responders, respectively). Further, it highlighted 28 proteins that were differentially abundant between responders and non-responders to $\mathrm{ACl}$, which were not found in the LF study, 16 of which were altered at baseline. The differential expression of two proteins (complement C1s subcomponent and matrix metalloproteinase 3) was confirmed biochemically. Combination of the ITRAQ and LF proteomic datasets generated in-depth SF proteome information that was used to generate interactome networks representing ACl success or failure. Functional pathways that are dysregulated in ACl non-responders were identified, including acute-phase response signalling.

Conclusions: Several candidate biomarkers for baseline prediction of ACl outcome were identified. A holistic overview of the SF proteome in responders and non-responders to ACl has been profiled, providing a better understanding of the biological pathways underlying clinical outcome, particularly the differential response to cartilage harvest in nonresponders.
\end{abstract}

Keywords: Autologous chondrocyte implantation (ACl), iTRAQ proteomics, Label-free quantitation proteomics, Synovial fluid, Cartilage repair, Complement C1S subcomponent, Matrix metalloproteinase 3, MMP3

\footnotetext{
* Correspondence: Karina.Wright@rjah.nhs.uk

${ }^{1}$ Institute of Science and Technology in Medicine, Keele University, Keele,

Staffordshire ST5 5BG, UK

${ }^{2}$ Robert Jones and Agnes Hunt Orthopaedic Hospital, Oswestry, Shropshire

SY10 7AG, UK

Full list of author information is available at the end of the article
}

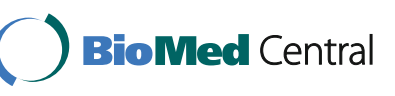

(c) The Author(s). 2018 Open Access This article is distributed under the terms of the Creative Commons Attribution 4.0 International License (http://creativecommons.org/licenses/by/4.0/), which permits unrestricted use, distribution, and reproduction in any medium, provided you give appropriate credit to the original author(s) and the source, provide a link to the Creative Commons license, and indicate if changes were made. The Creative Commons Public Domain Dedication waiver (http://creativecommons.org/publicdomain/zero/1.0/) applies to the data made available in this article, unless otherwise stated. 


\section{Background}

Identification of putative biomarkers that can be used to predict patient outcome prior to treatment for cartilage injury has been highlighted as a key initiative for the prevention of osteoarthritis (OA) by the Osteoarthritis Research Society International [1]. Further, in the United Kingdom, the National Health Service has increased the need to identify accurate prognostic biomarkers for application of the recent National Institute for Health and Care Excellence (NICE) recommendation for use of the cell therapy called autologous chondrocyte implantation (ACI) [2].

We recently published the first study [3], to our knowledge, in which a proteomic approach has been used with the aim of identifying candidate biomarkers to predict the success of ACI, a cellular therapy for the treatment of traumatic cartilage injury $[4,5]$. This therapy is composed of a two-stage procedure: During the initial surgery (stage I), healthy cartilage is harvested from a minor load-bearing region of the joint, then chondrocytes are isolated and culture is expanded for 3-4 weeks prior to a second surgery (stage II), in which the chondrocytes are implanted into the cartilage defect $[5,6]$. Approximately 500 patients have been treated with ACI in our centre, and despite an $81 \%$ success rate [7], we have yet to fully understand why some individuals do not respond well. We have identified a biomarker, aggrecanase-1, that, when its activity is undetectable pre-operatively, can be used together with known demographic and injury-associated risk factors to help predict ACI success $[8,9]$. However, we have yet to identify a biomarker (or panel of biomarkers) that can be used to accurately predict ACI failure. The identification of such a biomarker(s) for ACI and other cartilage repair strategies would allow for the better stratification of patients prior to joint surgery and may provide candidates for therapies to improve ACI success.

Proteomic analyses remain one of the most widely used methods to identify novel biomarker candidates and have previously been used to identify biomarkers of OA progression (as summarised by Hsueh et al. in 2014 [10]). The synovial fluid (SF) provides an attractive biological fluid for biomarker identification because it bathes the injured joint and therefore contains proteins that might reflect the whole joint environment. Proteomic profiling of the SF, however, is technically difficult owing to the broad dynamic range of proteins present within it $[7,8]$. Several unbiased global proteomic studies aimed at the identification of biomarkers within the SF have been completed. Nevertheless, the number of protein 'hits' has been somewhat limited, because researchers either have tended to profile SF with no pre-treatment to account for the wide range of proteins [11-16] or have depleted high-abundance proteins [17-22], meaning that the altered quantities of these proteins cannot be considered.
Isobaric tags for absolute and relative quantitation (iTRAQ) is reported to be the most accurate labelling method for quantifying comparative abundance of proteins [23]. When compared with label-free quantitation (LF) proteomics, iTRAQ quantitation has traditionally been considered a more accurate technique [24]; however, as mass spectrometers are improved, these techniques are becoming more comparable, and LF is becoming increasingly popular [25]. Unlike LF proteomics, iTRAQ uses isobaric tags to label the primary amines at the peptide level prior to pooling the samples to enable simultaneous identification and quantitation of the proteins. Fourplex and eightplex labels are available, enabling quantitation of up to eight conditions in a single analysis, thus minimising the number of mass spectrometry runs that can be cost-effective and timeefficient. However, when compared with LF, in which any number of samples can be analysed and compared, iTRAQ labelling limits the number of samples that can be compared, meaning biological replicate samples are often pooled together into relevant biological conditions. iTRAQ proteomics is a commonly used tool for the identification of biomarkers in a plethora of diseases. This proteomic approach has been used to profile the SF proteome [20,26], successfully identifying differentially abundant protein biomarker candidates for several diseases/conditions.

Our previous study highlighted the potential of using protein equalisation to study low-abundance proteins in human SF, but this identified few differentially abundant proteins in baseline SF, when comparing individuals who did or did not do well following cartilage repair therapy [1]. The aim of the present study therefore was to increase the number of protein biomarker candidates that could be identified for the pre-operative prediction of clinical outcome following ACI and to allow for the assessment of high-abundance proteins that may also strengthen the understanding of the biological processes underlying treatment success.

\section{Methods}

\section{SF collection and storage}

SF was collected as described previously [3, 8, 27] from the knee joints of patients who provided informed consent and following local research ethics committee approval. Immediately prior to both ACI surgeries, stage I (cartilage harvest) and stage II (chondrocyte implantation), $20 \mathrm{ml}$ of saline was injected into the joint and 20 rounds of leg flexion and extension were carried out to allow aspiration of as much SF as possible [3, 27]. SF was then centrifuged at $6000 \times g$ for 15 minutes at $4{ }^{\circ} \mathrm{C}$ and split into aliquots for long-term storage in liquid nitrogen. The dilution factor of the SF samples was calculated by comparing urea content in SF with matched 
blood plasma using a QuantiChrom ${ }^{\mathrm{Tm}}$ Urea Assay Kit (BioAssay Systems, Hayward, CA, USA) according to the manufacturer's instructions and as described previously $[3,8,28]$, and SF samples with a dilution factor > 10 were excluded from the study.

Clinical responders to ACI were defined as individuals who demonstrated a Lysholm score increase of $\geq 10$ points at 12 months post-treatment compared with their baseline score, as has been used previously [29-31]. The Lysholm score is a validated [32] patient-self assessment score encompassing knee pain and joint function that ranges from 0 to 100 , with 100 representing 'perfect' knee function [32, 33]. Thirteen patients were considered as non-responders to $\mathrm{ACI}$, demonstrating a mean decrease in Lysholm score of 14 points (range - 4 to 46), and 14 SF donors were considered responders with a mean improvement of 33 points (range 17-54).

\section{Sample preparation and analysis using iTRAQ proteomics (iTRAQ nanoLC-MS/MS)}

Total protein was quantified using a Pierce ${ }^{\text {Tw }} 660 \mathrm{~nm}$ Protein Assay (Thermo Fisher Scientific, Hemel Hempstead, UK) [34], and a total of $200 \mu \mathrm{g}$ of SF protein was pooled equally from the donors in each of the following experimental groups: stage I responders $(n=8)$, stage I nonresponders $(n=7)$, stage II responders $(n=12)$, and stage II non-responders $(n=12)$ (Table 1$)$. The pooled samples were then precipitated in six volumes of ice-cold acetone overnight at $-20{ }^{\circ} \mathrm{C}$. The precipitates were pelleted by centrifugation at $13,000 \times g$ for 10 minutes at $4{ }^{\circ} \mathrm{C}$ before being re-suspended in $200 \mu \mathrm{l}$ of triethylammonium bicarbonate buffer. Eighty-five micrograms of protein for each experimental sample were then subjected to reduction, alkylation (as instructed in the iTRAQ labelling kit; Applied Biosystems, Bleiswijk, The Netherlands). Sequencing Grade Modified Trypsin $(10 \mu \mathrm{g} / 85 \mu \mathrm{g}$ of protein; Promega, Madison, WI, USA) was then added to the samples for overnight digestion at $37{ }^{\circ} \mathrm{C}$. Tryptic digests were labelled with the iTRAQ tags according to the manufacturer's instructions before being pooled into one microcentrifuge tube prior to being dried in a vacuum centrifuge: 114 tag- stage II responders, 115 tag- stage II non-responders, 116 tag- stage I responders and 117 tagstage I non-responders.

iTRAQ-labelled peptides were resuspended in $0.6 \mathrm{ml}$ of loading buffer $(10 \mathrm{mM}$ monopotassium phosphate $\left[\mathrm{KH}_{2} \mathrm{PO}_{4}\right], 20 \%$ acetonitrile $[\mathrm{MeCN}], \mathrm{pH} 3.0$ ), followed by sonication. The $\mathrm{pH}$ was adjusted to 3.0 with $0.5 \mathrm{M}$ orthophosphoric acid $\left(\mathrm{H}_{3} \mathrm{PO}_{4}\right)$. The peptides were separated by strong cation exchange chromatography (SCX) as described previously [35]. A total of 14 SCX fractions were analysed by nano-electrospray ionisation-LC-MS/MS using a TripleTOF 5600 tandem mass spectrometer (AB Sciex, Framingham, MA, USA) as described previously [36].

The raw mass spectrometry data file was subsequently analysed using ProteinPilot 4.5 software with the Paragon

Table 1 Demographic data for patient participants whose samples from Stage I or Stage II were analysed who responded clinically (responders) or who did not respond (non-responders) to autologous chondrocyte implantation (ACl)

\begin{tabular}{|c|c|c|c|c|c|c|}
\hline & \multicolumn{2}{|l|}{ Stage I } & \multicolumn{2}{|l|}{ Stage II } & \multirow{2}{*}{$\begin{array}{l}\text { Mann-Whitney U test } \\
p \text { value } \\
(A) R \vee N R-S I ;(B) \\
R \vee N R-S I\end{array}$} & \multirow{2}{*}{$\begin{array}{l}\text { Mann-Whitney U test } \\
p \text { value) } \\
(\text { A)SI } \vee \text { SII-R; (B) } \\
\text { SI } \vee \text { SII- NR }\end{array}$} \\
\hline & $\begin{array}{l}\text { Responders } \\
(n=8)\end{array}$ & $\begin{array}{l}\text { Non-responders } \\
(n=7)\end{array}$ & $\begin{array}{l}\text { Responders } \\
(n=12)\end{array}$ & $\begin{array}{l}\text { Non-responders } \\
(n=12)\end{array}$ & & \\
\hline Difference in Lysholm score & $27(17-38)$ & $-8(-4$ to -17$)$ & $34(17-54)$ & $-11(-4$ to -46$)$ & (A) $0.0003 ;$ (B) $<0.0001$ & (A) 0.21 ; (B) 0.55 \\
\hline $\mathrm{BMl}, \mathrm{kg} / \mathrm{m}^{2}$ & $29(23-31)$ & $27(24-31)$ & $27(23-48)$ & $29(22-36)$ & (A) $0.94 ;$ (B) 0.54 & (A) 0.73 ; (B) 0.68 \\
\hline Age, years & $32(17-49)$ & $40(25-50)$ & $40(17-90)$ & $43(25-52)$ & (A) 0.28 ; (B) 0.92 & (A) 0.17 ; (B) 0.58 \\
\hline Male/female sex, $n$ & $8 / 0$ & $7 / 0$ & $11 / 1$ & $10 / 2$ & (A) $>0.99 ;(B)>0.99$ & (A) > 0.99; (B) 0.51 \\
\hline Smoker, $n$ & 1 & 2 & 1 & 3 & (A) 0.54 ; (B) 0.59 & (A) $>0.99 ;(B)>0.99$ \\
\hline Dilution factor of SF & $5(3-9)$ & $4(2-7)$ & $4(1-9)$ & $3(2-5)$ & (A) 0.48 ; (B) 0.25 & (A) 0.53 ; (B) 0.50 \\
\hline Total defect area, $\mathrm{cm}^{2}$ & $14(0.4-24)$ & $6(0.6-12)$ & $6(1-20)$ & $5(0.6-12)$ & (A) 0.74 ; (B) 0.35 & (A) 0.45 ; (B) 0.28 \\
\hline Patella defect, $n$ & 1 & 1 & 4 & 2 & (A) $>0.99$; (B) 0.64 & (A) 0.60 ; (B) > 0.99 \\
\hline LFC defect, $n$ & 2 & 0 & 0 & 0 & (A) 0.47 ; (B) $>0.99$ & (A) 0.15 ; (B) $>0.99$ \\
\hline LTP defect, $n$ & 1 & 0 & 0 & 0 & (A) $>0.99 ;(B)>0.99$ & (A) 0.15 ; (B) $>0.99$ \\
\hline MFC defect, $n$ & 2 & 2 & 1 & 6 & (A) $>0.99$; (B) 0.07 & (A) 0.54 ; (B) 0.63 \\
\hline Trochlea defect, $n$ & 0 & 3 & 2 & 1 & (A) 0.20 ; (B) $>0.99$ & (A) 0.49 ; (B) 0.12 \\
\hline Multiple defects, $n$ & 1 & 0 & 1 & 1 & (A) > 0.99; (B) > 0.99 & (A) $>0.99 ;(B)>0.99$ \\
\hline Unknown defect location, $n$ & 1 & 1 & 4 & 2 & (A) $>0.99$; (B) 0.64 & (A) 0.60 ; (B) > 0.99 \\
\hline
\end{tabular}

Footnote: None of the demographic parameters, other than a difference in Lysholm score, showed differences between responders (R) and non-responders (NR) among individuals whose SF from stage I (SI) or stage II (SII) was compared, nor were there differences between individuals who were either responders or nonresponders when we compared stage I and stage II samples ( $p \geq 0.05$ by Mann-Whitney $U$ test). Data are median (range). Abbreviations: BMI Body mass index, LFC Lateral femoral condyle, LTP Lateral tibial plateau, MFC Medial femoral condyle 
and ProGroup ${ }^{\mathrm{Tw}}$ algorithms (AB Sciex) against the human sequences in the UniProtKB/Swiss-Prot database (downloaded in December 2012). Searches were performed using the pre-set iTRAQ settings in ProteinPilot. Trypsin was selected as the cleavage enzyme and methyl methanethiosulphonate for the modification of cysteines with a 'thorough ID' search effort. ProteinPilot's bias correction assumes that most proteins do not change in expression. Finally, detected proteins were reported with a protein threshold [unused ProtScore (confidence)] $>0.05$ and used in the quantitative analysis if they were identified with two or more unique peptides with $95 \%$ confidence or above. $p$ Values and false discovery rates for the iTRAQ ratios were calculated using the ProteinPilot software. Proteins with iTRAQ ratios with $p$ values $\leq 0.05$ and with differential abundance of greater than or equal to \pm 2.0 -fold change (FC) were used in further analysis.

\section{Verification of iTRAQ nanoLC-MS/MS results using enzyme linked immunosorbent assay}

Two proteins of biological relevance were measured by enzyme-linked immunosorbent assay (ELISA) in the nonpooled samples to verify the MS findings. Firstly, complement $\mathrm{C} 1 \mathrm{~S}$ subcomponent $(\mathrm{C} 1 \mathrm{~s})$ was selected because this protein demonstrated differential abundance between responders and non-responders to ACI within the baseline SF (prior to stage I surgery) and therefore could have potential as a biomarker of outcome prediction. C1s was assessed using a human ELISA (CUSABIO, Houston, TX, USA). Samples were first assayed using a 1:100 dilution in assay sample diluent, and for those samples that were undetectable in the assay, the assay was repeated using undiluted samples. Secondly, matrix metalloproteinase 3 (MMP3) was selected to investigate the differential response to stage I surgery (i.e., the proteomic shift between stages I and II) in non-responders to ACI. MMP3 was assessed using a human Quantikine ELISA (R\&D Systems, Abingdon, UK). Samples were diluted 1:100 in assay kit diluent prior to assessment. Both ELISAs were carried out according to the manufacturer's instructions, and protein concentrations were normalised to the sample dilution factor. Statistical analysis was performed using Prism version 6.0 software (GraphPad Software, La Jolla, CA, USA). Student's $t$ tests were used to assess differential abundance.

\section{Assessment of protein overlap identified using the two proteomic approaches}

To assess whether the use of two independent proteomic approaches allows for a greater number of significant protein changes to be identified, the datasets from this study (iTRAQ nanoLC-MS/MS [nLC-MS/MS]) and our previously published study assessing the same patient samples (LF LC-MS/MS [3]) were compared with one another. Venn diagrams were plotted using VENNY 2.1.0 software [37] to assess the overlap of differentially abundant proteins that were identified via the two approaches.

\section{Pathway and network analysis of proteomic datasets}

The datasets generated using both proteomic approaches were combined. Specifically, proteins that were differentially expressed $(\geq 1.2 \mathrm{FC} ; p \leq 0.05)$ in each biological comparison (e.g., stage I responders versus nonresponders) in either proteomic approach were merged into a single dataset. A modest FC cutoff was used to ensure that the greatest number of differentially abundant proteins could be included in the pathway and network analyses, as has been done previously $[3,18]$. The iTRAQ nLC-MS/MS dataset independently, as well as when merged with the LF dataset, was analysed using pathway enrichment analysis (Ingenuity Pathway Analysis; Qiagen Bioinformatics, Redwood City, CA, US) to identify and visualise affected canonical pathways. Pathways with a significance level of $p \leq 0.005$ were considered statistically significant (Fisher's exact test).

The merged LF and iTRAQ nLC-MS/MS datasets of proteomic response to cartilage harvest (e.g., differential abundance between stages I and II) in responders and non-responders were assessed using interactome network analysis, which is an unbiased mathematical method of visualising and interpreting complex interactions between large numbers of molecules [38]. Interactome networks are made up of nodes (the individual objects being studied, such as proteins) and edges (the connections between the objects, such as known protein-protein interactions) [39]. By studying groups of proteins that are highly interconnected, known as modules, key functions within an interactome network can be highlighted [39]. Conducting interactome network analysis alongside pathway enrichment analysis allows for greater confidence in the selection of candidate pathways or molecules for further study, because these represent two independent methods of mapping the data: known protein-protein interactions and text mining, respectively. The interactions between the differentially abundant proteins were assessed using the PINA4MS (Protein Interaction Network Analysis For Multiple Sets) app [40] in Cytoscape version 3.0 to generate network models based on protein-protein interactions. These models were based either on only those proteins identified in the proteomic analyses (non-inferred nodes) or on proteins identified in the proteomic analyses alongside their inferred interactions (inferred nodes) [41]. The ModuLand (version 2.8.3) algorithm [42] was applied to the interactome networks in Cytoscape version 3.0 to identify highly connected clusters of proteins (modules) that demarcate the hierarchical structure of the interactome network. The biological function of each module was assessed by analysing the proteins identified within 
each module using the pathway analysis tool in Reactome software $[43,44]$. The significance of the pathway functions identified in Reactome was determined by Fisher's exact test, and $p \leq 0.05$ was considered statistically significant.

\section{Results}

The proteomic data derived from this study have been deposited in the PRoteomics IDEntifications (PRIDE) ProteomeXchange and can be accessed using the identifier [PXD008321].

\section{Identification of proteins to predict $\mathrm{ACl}$ outcome prior to stage I or stage II}

iTRAQ nLC-MS/MS highlighted 16 proteins (greater than or equal to $\pm 2.0 \mathrm{FC} ; p \leq 0.05$ ) that were differentially abundant between responders and non-responders to ACI at baseline (immediately prior to stage I) (Table 2). Prior to stage II of the ACI procedure, 12 proteins displayed differential abundance between responders and nonresponders (Table 3).

At both stages of treatment, SF analysed using iTRAQ nLC-MS/MS identified a greater number of differentially abundant proteins between individuals who did or did not respond well to ACI compared with SF that had undergone protein normalisation using the ProteoMiner $^{\mathrm{TM}}$ protein enrichment kit (Bio-Rad Laboratories,
Hercules, CA, USA) and LF LC-MS/MS analysis [3]. Further, the two proteomic techniques identified no common differentially abundant proteins. The two proteins selected and assessed by ELISA (C1s and MMP3) could verify the iTRAQ nLC-MS/MS (Fig. 1).

\section{Differential abundance of proteins at stage II compared with stage I of $\mathrm{ACl}$}

Proteomic profiling of the SF using iTRAQ nLC-MS/MS highlighted a considerable effect of the cartilage harvest procedure (stage I) in both responders and nonresponders, with 70 and 54 proteins being differentially abundant between stages I and II, respectively, thus strengthening the similar findings derived from the analysis of these samples using LF LC-MS/MS [3]. Interestingly, the iTRAQ nLC-MS/MS and LF LC-MS/MS identified no common protein differences between stage I and stage II in the clinical responders (70 differentially abundant proteins identified by iTRAQ nLC-MS/MS and 14 identified by LF LC-MS/MS) (Table 4). This lack of overlap between the two proteomic techniques is highlighted in Fig. 2. There were, however, six proteins (gelsolin, vitamin K-dependent protein S, C4b-binding protein alpha chain, fibrinogen alpha chain, fibrinogen beta chain and fibrinogen gamma chain) that were identified by both proteomic techniques in the nonresponders, all of which showed commonality in the

Table 2 Fold change of proteins that are differentially abundant in the synovial fluid of clinical non-responders compared with clinical responders to autologous chondrocyte implantation (ACI) immediately prior to stage I

\begin{tabular}{|c|c|c|c|c|}
\hline \multicolumn{2}{|l|}{ Protein } & \multirow[t]{2}{*}{ Fold change } & \multicolumn{2}{|c|}{ Identification method } \\
\hline Description & Accession no. & & LF LC-MS/MS & iTRAQ nLC-MS/MS \\
\hline Complement C1S subcomponent & P09871 & -5.15 & & + \\
\hline Haptoglobin & P00738 & -4.49 & & + \\
\hline Mesencephalic astrocyte-derived neurotrophic factor & P55145 & 2.15 & & + \\
\hline Plasma protease C1 inhibitor & P05155 & 2.19 & & + \\
\hline Immunoglobulin kappa chain V-II region MIL & P01615 & 2.60 & + & \\
\hline Bifunctional glutamate/proline-transfer RNA ligase & P07814 & 2.61 & & + \\
\hline Pigment epithelium-derived factor & P36955 & 3.13 & & + \\
\hline Apolipoprotein A-IV & P06727 & 3.19 & & + \\
\hline Apolipoprotein L1 & 014791 & 3.19 & & + \\
\hline N-acetylglucosamine-6-sulphatase & P15586 & 3.25 & & + \\
\hline Retinol-binding protein 4 & P02753 & 3.34 & & + \\
\hline Inter-alpha-trypsin inhibitor heavy chain H1 & P19827 & 3.37 & & + \\
\hline Extracellular matrix protein 1 & Q16610 & 3.77 & & + \\
\hline Lumican & P51884 & 3.80 & & + \\
\hline Histidine-rich glycoprotein & P04196 & 3.84 & & + \\
\hline Endoplasmin & P14625 & 4.37 & & + \\
\hline Serum paraoxonase/arylesterase 1 & P27169 & 4.41 & & + \\
\hline
\end{tabular}

Footnote: Differential abundance was denoted by greater than or equal to \pm 2.0 -fold change; $p \leq 0.05$; protein identified by at least two unique peptides. Positive numbers denote higher abundance in non-responders than in responders. Proteins were identified using either protein dynamic compression coupled with label-free quantitation LC-MS/MS or no protein dynamic compression with isobaric tags for absolute and relative quantitation (iTRAQ) LC-MS/MS 
Table 3 Fold change of proteins that are differentially abundant in the synovial fluid of clinical non-responders compared with clinical responders to autologous chondrocyte implantation (ACl) immediately prior to stage II

\begin{tabular}{|c|c|c|c|c|}
\hline \multicolumn{2}{|l|}{ Protein } & \multirow[t]{2}{*}{ Fold Change } & \multicolumn{2}{|c|}{ Identification method } \\
\hline Description & Accession & & LF LC-MS/MS & iTRAQ nLC-MS/MS \\
\hline 40S Ribosomal protein S14 & P62263 & -8.63 & & + \\
\hline Kinectin & Q86UP2 & -6.20 & & + \\
\hline Apolipoprotein C-III & P02656 & -2.78 & & + \\
\hline High-mobility group protein B1 & P09429 & -2.56 & & + \\
\hline Kininogen-1 & P01042 & 2.27 & & + \\
\hline 26S Protease regulatory subunit 7 & P35998 & 2.34 & + & \\
\hline 26S Proteasome non-ATPase regulatory subunit 13 & Q9UNM6 & 2.43 & + & \\
\hline Alpha-enolase & P06733 & 2.56 & & + \\
\hline Alpha-2-HS-glycoprotein & P02765 & 2.78 & & + \\
\hline Hemopexin & P02790 & 2.88 & & + \\
\hline Ferritin light chain & P02792 & 2.91 & + & \\
\hline Platelet factor 4 & P02776 & 3.26 & + & \\
\hline Thrombospondin-1 & P07996 & 3.40 & + & \\
\hline Nucleosome assembly protein 1-like 1 & P55209 & 4.94 & + & \\
\hline Cofilin-1 & P23528 & 7.08 & + & \\
\hline EH domain-containing protein 1 & Q9H4M9 & 7.30 & + & \\
\hline Haemoglobin subunit delta & P02042 & 8.09 & & + \\
\hline Protein S100-A6 & P06703 & 8.39 & & + \\
\hline T-complex protein 1 subunit eta & Q99832 & 8.43 & + & \\
\hline Haemoglobin subunit beta & P68871 & 32.81 & & + \\
\hline Haemoglobin subunit alpha & P69905 & 44.06 & & + \\
\hline
\end{tabular}

Footnote: Differential abundance was denoted by greater than or equal to \pm 2.0 -fold change; $p \leq 0.05$; protein identified by at least two unique peptides. Positive numbers denote higher abundance in non-responders than in responders. Proteins were identified using either protein dynamic compression coupled with label-free quantitation LC-MS/MS or no protein dynamic compression with isobaric tags for absolute and relative quantitation (iTRAQ) LC-MS/MS

direction of protein shift across the MS platforms, with iTRAQ nLC-MS/MS consistently resulting in greater differences in abundance than those identified from the LF LC-MS/MS data. A total of 54 protein abundance changes between stages I and II in non-responders were identified using iTRAQ nLC-MS/MS, and 55 protein differences were identified by LF LC-MS/MS (Table 5 and Fig. 2).

\section{iTRAQ nLC-MS/MS confirmed a significant response to} cartilage harvest procedure (stage I) in nonresponders to $\mathrm{ACl}$ Pathway analysis of the iTRAQ nLC-MS/MS-identified proteins, using the pathway enrichment tools in Ingenuity Pathway Analysis, suggested that the proteins which were differentially abundant at stage II compared with stage I in non-responders are likely to impact numerous canonical pathways, many of which were confirmatory of the previously published functional pathways identified from the LF nLC-MS/MS-derived proteins [3]. These functional pathways included acute-phase response signalling $\left(p=2.93 \times 10^{-1}\right)$, the complement system $\left(p=2.11 \times 10^{-1}\right)$ and liver $\mathrm{X}$ receptor/retinoic $\mathrm{X}$ receptor signalling $\left(p=1.95 \times 10^{-1}\right)$. Moreover, many more functional pathways were affected as a result of the proteins that were differentially abundant in response to stage II compared with stage I in nonresponders compared with responders (Additional file 1: Tables S1 and S2), reiterating that the SF proteomic response to cartilage harvest is more distinct in nonresponders to $\mathrm{ACI}$.

\section{Similar pathways were identified from the differentially abundant proteins identified in ITRAQ nLC-MS/MS and LF LC-MS/MS analyses}

Both iTRAQ nLC-MS/MS and LF LC-MS/MS analyses resulted in acute-phase response signalling being highlighted as one of the most significantly affected pathways in response to cartilage harvest in nonresponders to $\mathrm{ACI}$; therefore, this pathway was further assessed. Figure 3 highlights that analysis of the SF proteome using the two independent proteomic techniques resulted in a greater number of differentially abundant downstream proteins being identified. In 


\section{Complement C1S Subcomponent}

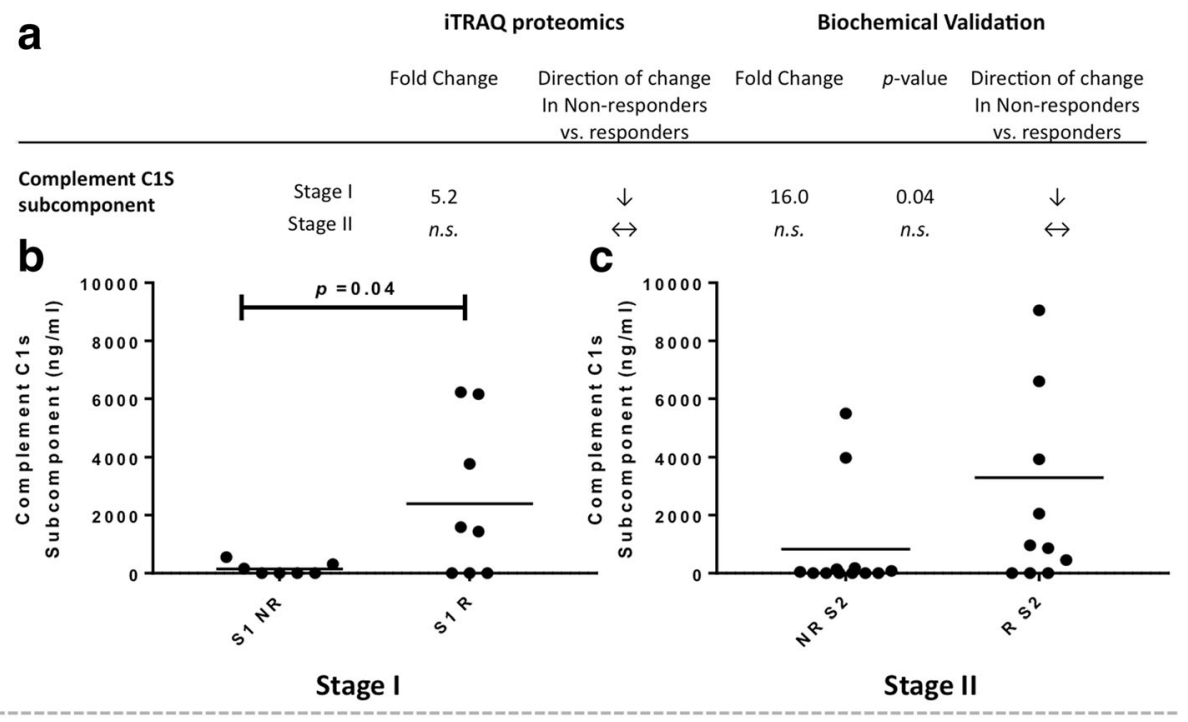

\section{Matrix Metalloproteinase-3}



Fig. 1 Biochemical validation of differentially abundant proteins identified using isobaric tagging for relative and absolute quantitation (iTRAQ) proteomics. $\mathbf{a}$ and $\mathbf{d}$ Differential abundance of complement C1S subcomponent (C1S) and matrix metalloproteinase 2 as measured by iTRAQ MS and biochemical enzyme-linked immunosorbent assay (ELISA), respectively. Quantitative ELISA confirmed that (b) C1S is significantly decreased in the synovial fluid (SF) of non-responders (NR) compared with responders (R) to autologous chondrocyte implantation (ACl) prior to cartilage harvest (stage I [S1]; $p=0.04$ by Student's $t$ test) (c) but was not significantly differentially abundant prior to chondrocyte implantation (stage II [S2]). Matrix metalloproteinase 3 (MMP3) (e) was not differentially abundant in response to cartilage harvest in ACl responders (f) but was biochemically confirmed to be differentially abundant in the SF of non-responders between stages I and II of the ACl procedure ( $p=0.001$ by Student's $t$ test)

addition, many complementary proteins have been identified when comparing these datasets, with the vast majority of proteins that are predicted to be increased in the plasma (the standard bodily fluid referred to in Ingenuity Pathway Analysis) during the acute-phase response being more abundant in the SF at stage II than at stage I and vice versa.

Because the results of the two proteomic approaches seem to be complementary to one another, the two datasets were combined to generate a more comprehensive profile of the SF proteome. Ingenuity Pathway Analysis again identified many functional pathways similar to those identified via the independent LF LC-MS/MS and ITRAQ nLC-MS/ MS datasets. The most significant canonical pathways associated with the non-responder response to cartilage harvest (stage II versus stage I) were acute-phase response signalling $\left(p=1.10 \times 10^{-9}\right)$, intrinsic prothrombin activation pathway $\left(p=3.43 \times 10^{-7}\right)$ and the complement system $(p=$ 
Table 4 Fold change of proteins that are differentially abundant in the synovial fluid of clinical responders at stage II compared with stage I of autologous chondrocyte implantation (ACl)

\begin{tabular}{|c|c|c|c|c|}
\hline \multicolumn{2}{|l|}{ Protein } & \multirow[t]{2}{*}{ Fold change } & \multicolumn{2}{|c|}{ Identification method } \\
\hline Description & Accession no. & & LF LC-MS/MS & iTRAQ nLC-MS/MS \\
\hline Microtubule-associated protein 1B & P46821 & -20.65 & + & \\
\hline 40S Ribosomal protein S14 & P62263 & -16.75 & & + \\
\hline Protein disulphide-isomerase A6 & Q15084 & -7.59 & & + \\
\hline Nucleolin & P19338 & -5.11 & & + \\
\hline Histone H1.2 & P16403 & -3.84 & & + \\
\hline Stress-induced-phosphoprotein 1 & P31948 & -3.63 & & + \\
\hline Complement factor D & P00746 & -3.44 & & + \\
\hline SH3 domain-binding glutamic acid-rich-like protein & O75368 & -3.44 & & + \\
\hline Heterogeneous nuclear ribonucleoprotein $U$ & Q00839 & -3.40 & & + \\
\hline 78 kDa Glucose-regulated protein & P11021 & -3.25 & & + \\
\hline Cartilage oligomeric matrix protein & P49747 & -3.10 & & + \\
\hline Annexin A2 & P07335 & -2.96 & & + \\
\hline Mesencephalic astrocyte-derived neurotrophic factor & P55145 & -2.86 & & + \\
\hline Kinectin & Q86UP2 & -2.81 & & + \\
\hline Complement factor H-related protein 3 & Q02985 & -2.77 & + & \\
\hline Phosphatidylethanolamine-binding protein 1 & P30086 & -2.51 & & + \\
\hline Peroxiredoxin-4 & Q13162 & -2.49 & + & \\
\hline Regucalcin & Q15493 & -2.44 & & + \\
\hline Malate dehydrogenase, mitochondrial & P40926 & -2.44 & & + \\
\hline $\mathrm{N}$-acetylglucosamine-6-sulphatase & P15586 & -2.31 & & + \\
\hline Gelsolin & P06396 & -2.27 & & + \\
\hline Alpha-endosulfine & O43768 & -2.25 & & + \\
\hline Peptidyl-prolyl cis-trans isomerase FKBP3 & Q00688 & -2.11 & & + \\
\hline Hemopexin & P02790 & 2.05 & & + \\
\hline Serum paraoxonase/arylesterase 1 & P27169 & 2.07 & & + \\
\hline Secreted phosphoprotein 24 & Q13103 & 2.10 & + & \\
\hline Heparin cofactor 2 & P05546 & 2.13 & & + \\
\hline Ferritin light chain & P02792 & 2.21 & + & \\
\hline Attractin & O75882 & 2.21 & & + \\
\hline Ig gamma-2 chain $C$ region & P01859 & 2.23 & & + \\
\hline Plasma kallikrein & P03952 & 2.24 & & + \\
\hline Chondroitin sulphate proteoglycan 4 & Q6UVK1 & 2.35 & + & \\
\hline Collagen alpha-2(I) chain & P08123 & 2.37 & + & \\
\hline Collagen alpha-1(V) chain & P20908 & 2.54 & + & \\
\hline CD5 antigen-like & O43866 & 2.58 & & + \\
\hline Phospholipid transfer protein & P55058 & 2.63 & & + \\
\hline Insulin-like growth factor-binding protein complex acid labile subunit & P35858 & 2.68 & & + \\
\hline Prothrombin & P00734 & 2.68 & & + \\
\hline Beta-2-glycoprotein 1 & P02749 & 2.78 & & + \\
\hline Collagen alpha-2(V) chain & P05997 & 2.84 & + & \\
\hline Plasma protease $\mathrm{C} 1$ inhibitor & P05155 & 2.91 & & + \\
\hline Serum amyloid $\mathrm{P}$ component & P02743 & 2.91 & & + \\
\hline Complement C1q subcomponent subunit B & P02746 & 3.01 & & + \\
\hline Collagen alpha-1(I) chain & P02452 & 3.05 & + & \\
\hline
\end{tabular}


Table 4 Fold change of proteins that are differentially abundant in the synovial fluid of clinical responders at stage II compared with stage I of autologous chondrocyte implantation (ACI) (Continued)

\begin{tabular}{|c|c|c|c|c|}
\hline \multicolumn{2}{|l|}{ Protein } & \multirow[t]{2}{*}{ Fold change } & \multicolumn{2}{|c|}{ Identification method } \\
\hline Description & Accession no. & & LF LC-MS/MS & iTRAQ nLC-MS/MS \\
\hline Alpha-2-antiplasmin & P08697 & 3.10 & & + \\
\hline Alpha-1B-glycoprotein & P04217 & 3.19 & & + \\
\hline Complement factor B & P00751 & 3.25 & & + \\
\hline Complement component C7 & P10643 & 3.40 & & + \\
\hline Vitamin K-dependent protein S & P07225 & 3.42 & & + \\
\hline Apolipoprotein E & P02649 & 3.44 & & + \\
\hline Alpha-1-antichymotrypsin & P01011 & 3.44 & & + \\
\hline Carboxypeptidase $\mathrm{N}$ subunit 2 & P22792 & 3.53 & & + \\
\hline Vitronectin & P04004 & 3.63 & & + \\
\hline Inter-alpha-trypsin inhibitor heavy chain H3 & Q06033 & 3.66 & & + \\
\hline Complement $\mathrm{C} 5 \mathrm{O}$ & P01031 & 4.00 & & + \\
\hline Plasminogen & P00747 & 4.06 & & + \\
\hline Kininogen 1 & P01042 & 4.17 & & + \\
\hline Platelet factor 4 & P02776 & 4.26 & + & \\
\hline Inter-alpha-trypsin inhibitor heavy chain $\mathrm{H} 2$ & P19823 & 4.49 & & + \\
\hline Periostin & Q15063 & 4.57 & + & \\
\hline Apolipoprotein L1 & 014791 & 4.61 & & + \\
\hline Protein 4.1 & P11171 & 4.66 & + & \\
\hline 26S Proteasome non-ATPase regulatory subunit 13 & Q9UNM6 & 4.78 & + & \\
\hline Inter-alpha-trypsin inhibitor heavy chain $\mathrm{H} 1$ & P19827 & 5.01 & & + \\
\hline Inter-alpha-trypsin inhibitor heavy chain $\mathrm{H} 4$ & Q14624 & 5.06 & & + \\
\hline Complement $\mathrm{C} 1 \mathrm{r}$ subcomponent & P00736 & 5.15 & & + \\
\hline Complement component C6 & P13671 & 5.45 & & + \\
\hline Complement factor $\mathrm{H}$ & P08603 & 5.50 & & + \\
\hline Catalase & P04040 & 5.60 & & + \\
\hline Ficolin-3 & O75636 & 6.43 & & + \\
\hline C4b-binding protein alpha chain & P04003 & 7.05 & & + \\
\hline Ceruloplasmin & P00450 & 7.51 & & + \\
\hline Pregnancy zone protein & P20742 & 8.09 & & + \\
\hline Fibrinogen alpha chain & P02671 & 8.40 & & + \\
\hline Apolipoprotein M & 095445 & 9.04 & & + \\
\hline Protein S100-A6 & P06703 & 9.82 & & + \\
\hline Haemoglobin subunit alpha & P69905 & 9.82 & & + \\
\hline Complement C1s subcomponent & P09871 & 10.00 & & + \\
\hline Ig mu chain $C$ region & P01871 & 12.13 & & + \\
\hline Haptoglobin & P00738 & 13.68 & & + \\
\hline Fibrinogen beta chain & P02675 & 16.90 & & + \\
\hline Haemoglobin subunit beta & P68871 & 19.41 & & + \\
\hline Fibrinogen gamma chain & P02679 & 23.55 & & + \\
\hline
\end{tabular}

Footnote: Differential abundance was denoted by greater than or equal to \pm 2.0 -fold change; $p \leq 0.05$; protein identified by at least two unique peptides. Positive numbers denote higher abundance at stage II than at stage I. Proteins were identified using either protein dynamic compression coupled with label-free quantitation LC-MS/MS or no protein dynamic compression with isobaric tags for absolute and relative quantitation (iTRAQ) LC-MS/MS 
Table 5 Fold change of proteins that are differentially abundant in the synovial fluid of clinical non-responders at stage II compared with stage I

\begin{tabular}{|c|c|c|c|c|}
\hline \multicolumn{2}{|l|}{ Protein } & \multirow{2}{*}{$\begin{array}{l}\text { Fold } \\
\text { change }\end{array}$} & \multicolumn{2}{|c|}{ Identification method } \\
\hline Description & Accession & & LF LC-MS/MS & iTRAQ nLC-MS/MS \\
\hline Protein S100-A6 & P06703 & -4.49 & & + \\
\hline Annexin A1 & P04083 & -4.13 & & + \\
\hline Haemoglobin subunit beta & P68871 & -4.09 & & + \\
\hline Complement factor D & P00746 & -3.87 & & + \\
\hline Perilipin-4 & Q96Q06 & -3.87 & + & \\
\hline Gelsolin & P06396 & -3.31 & & + \\
\hline Gelsolin & $\underline{P 06396}$ & -1.68 & + & \\
\hline Syntaxin 7 & 015400 & -3.31 & + & \\
\hline Fermitin family homolog 3 & Q86UX7 & -3.29 & + & \\
\hline Histone H1.2 & P16403 & -3.13 & & + \\
\hline Transaldolase & P37837 & -3.08 & & + \\
\hline Neuroblast differentiation-associated protein AHNAK & Q09666 & -2.78 & + & \\
\hline Heterogeneous nuclear ribonucleoprotein $\mathrm{K}$ & P61978 & -2.69 & + & \\
\hline Hyaluronan and proteoglycan link protein 3 & Q96\$86 & -2.65 & + & \\
\hline Alpha-enolase & P06733 & -2.63 & & + \\
\hline ATP-citrate synthase & P53396 & -2.63 & + & \\
\hline Annexin A2 & P07355 & -2.56 & & + \\
\hline Fatty acid-binding protein, epidermal & Q01469 & -2.43 & + & \\
\hline Peroxiredoxin-1 & Q06830 & -2.20 & + & \\
\hline Tripeptidyl-peptidase 1 & 014773 & -2.19 & + & \\
\hline Insulin-like growth factor-binding protein 6 & P24592 & -2.13 & + & \\
\hline $\mathrm{Na}^{+} / \mathrm{H}^{+}$exchange regulatory cofactor NHE-RF1 & 014745 & -2.11 & + & \\
\hline Peroxiredoxin-6 & P30041 & -2.08 & + & \\
\hline Histamine N-methyltransferase & P50135 & -2.07 & + & \\
\hline Mortality factor 4-like protein 1 & Q9UBU8 & -2.06 & + & \\
\hline Transcription elongation factor A protein 1 & P23193 & -2.06 & + & \\
\hline Cartilage acidic protein 1 & Q9NQ79 & -2.03 & & + \\
\hline 2',3'-cyclic-nucleotide 3'-phosphodiesterase & P09543 & -1.20 & + & \\
\hline Fructose-bisphosphate aldolase A & P04075 & -1.97 & + & \\
\hline Leucine zipper transcription factor-like protein 1 & Q9NQ48 & -1.94 & + & \\
\hline Protein S100-A13 & Q99584 & -1.94 & + & \\
\hline 40 S Ribosomal protein S3 & P23396 & -1.93 & + & \\
\hline Filamin-A & P21333 & -1.92 & + & \\
\hline Microtubule-associated protein RP/EB family member 1 & Q15691 & -1.92 & + & \\
\hline Nuclear migration protein nudC & Q9Y266 & -1.90 & + & \\
\hline Prostaglandin E synthase 3 & Q15185 & -1.85 & + & \\
\hline Stress-induced phosphoprotein 1 & P31948 & -1.85 & + & \\
\hline Cytokine-like protein 1 & Q9NRR1 & -1.81 & + & \\
\hline Plastin-2 & P13796 & -1.81 & + & \\
\hline Coronin-1C & Q9ULV4 & -1.80 & + & \\
\hline Vinculin & P18206 & -1.80 & + & \\
\hline Cathepsin K & P43235 & -1.79 & + & \\
\hline Hsc70-interacting protein & P50502;Q8IZP2 & -1.76 & + & \\
\hline Putative phospholipase B-like 2 & Q8NHP8 & -1.74 & + & \\
\hline
\end{tabular}


Table 5 Fold change of proteins that are differentially abundant in the synovial fluid of clinical non-responders at stage II compared with stage I (Continued)

\begin{tabular}{|c|c|c|c|c|}
\hline \multicolumn{2}{|l|}{ Protein } & \multirow{2}{*}{$\begin{array}{l}\text { Fold } \\
\text { change }\end{array}$} & \multicolumn{2}{|c|}{ Identification method } \\
\hline Description & Accession & & LF LC-MS/MS & iTRAQ nLC-MS/MS \\
\hline Spectrin beta chain, erythrocytic & P11277 & -1.73 & + & \\
\hline Complement factor I & P05156 & 2.11 & & + \\
\hline Alpha-1-antichymotrypsin & P01011 & 2.22 & & + \\
\hline Titin & Q8WZ42 & 2.23 & & + \\
\hline Cytoplasmic dynein 1 heavy chain 1 & Q14204 & 2.23 & + & \\
\hline F-actin-capping protein subunit beta & P47756 & 2.25 & + & \\
\hline Mannan-binding lectin serine protease 1 & P48740 & 2.26 & + & \\
\hline Serum amyloid P-component & P02743 & 2.27 & & + \\
\hline Complement component C6 & P13671 & 2.29 & & + \\
\hline Thrombospondin-3 & P49746 & 2.36 & + & \\
\hline Soluble scavenger receptor cysteine-rich domain-containing protein SSC5D & $\mathrm{A} 1 \mathrm{~L} 4 \mathrm{H} 1$ & 2.39 & + & \\
\hline Plasma kallikrein & P03952 & 2.42 & & + \\
\hline Complement factor B & P00751 & 2.47 & & + \\
\hline Afamin & P43652 & 2.47 & & + \\
\hline Vitamin K-dependent protein S & P07225 & 2.49 & + & \\
\hline Vitamin K-dependent protein S & P07225 & 3.08 & & + \\
\hline Integrin beta-like protein 1 & O95965 & 2.51 & + & \\
\hline C4b-binding protein beta chain & P20851 & 2.55 & + & \\
\hline Fibronectin & P02751 & 2.58 & + & \\
\hline Clusterin & P10909 & 2.65 & & + \\
\hline Vitronectin & P04004 & 2.68 & & + \\
\hline Bifunctional glutamate/proline-transfer RNA ligase & P07814 & 2.70 & & + \\
\hline Nucleobindin 1 & Q02818 & 2.71 & + & \\
\hline Complement component C9 & P02748 & 2.75 & & + \\
\hline Zinc-alpha-2-glycoprotein & P25311 & 2.75 & & + \\
\hline Complement $\mathrm{C} 1 \mathrm{r}$ subcomponent & P00736 & 2.83 & & + \\
\hline Heparin cofactor 2 & P05546 & 2.83 & & + \\
\hline Ferritin light chain & P02792 & 2.84 & + & \\
\hline Proteoglycan 4 & Q92954 & 2.88 & & + \\
\hline C4b-binding protein alpha chain & P04003 & 2.91 & + & \\
\hline C4b-binding protein alpha chain & P04003 & 10.38 & & + \\
\hline Matrix metalloproteinase 3 & P08254 & 2.91 & & + \\
\hline Attractin & O75882 & 2.94 & & + \\
\hline Insulin-like growth factor-binding protein complex acid labile subunit & P35858 & 3.02 & & + \\
\hline Alpha-1B-glycoprotein & P04217 & 3.05 & & + \\
\hline Fibrinogen alpha chain & P02671 & 3.10 & + & \\
\hline Fibrinogen alpha chain & P02671 & 11.91 & & + \\
\hline Lumican & P51884 & 3.13 & & + \\
\hline Chondroitin sulphate proteoglycan 4 & Q6UVK1 & 3.16 & + & \\
\hline Collagen alpha-2(V) chain & P05997 & 3.19 & + & \\
\hline Complement C2 & P06681 & 3.22 & & + \\
\hline Fibrinogen beta chain & P02675 & 3.25 & + & \\
\hline Fibrinogen beta chain & P02675 & 18.37 & & + \\
\hline Secreted phosphoprotein 24 & Q13103 & 3.26 & + & \\
\hline
\end{tabular}


Table 5 Fold change of proteins that are differentially abundant in the synovial fluid of clinical non-responders at stage II compared with stage I (Continued)

\begin{tabular}{|c|c|c|c|c|}
\hline \multicolumn{2}{|l|}{ Protein } & \multirow{2}{*}{$\begin{array}{l}\text { Fold } \\
\text { change }\end{array}$} & \multicolumn{2}{|c|}{ Identification method } \\
\hline Description & Accession & & LF LC-MS/MS & iTRAQ nLC-MS/MS \\
\hline Matrix metalloproteinase 1 & P03956 & 3.33 & + & \\
\hline Latent-transforming growth factor beta-binding protein 1 & Q14766 & 3.45 & + & \\
\hline Phospholipid transfer protein & P55058 & 3.47 & & + \\
\hline Inter-alpha-trypsin inhibitor heavy chain $\mathrm{H} 3$ & Q06033 & 3.47 & & + \\
\hline Complement $\mathrm{C} 1 \mathrm{q}$ tumour necrosis factor-related protein 3 & Q9BXJ4 & 3.50 & + & \\
\hline Adipocyte enhancer-binding protein 1 & Q8IUX7;Q8N436 & 3.51 & + & \\
\hline Adiponectin & Q15848 & 3.52 & + & \\
\hline Fibrinogen gamma chain & P02679 & 3.79 & + & \\
\hline Fibrinogen gamma chain & P02679 & 18.37 & & + \\
\hline Plasminogen & P00747 & 3.84 & & + \\
\hline Apolipoprotein C-II & P02655 & 3.94 & & + \\
\hline CD5 antigen-like & 043866 & 4.17 & & + \\
\hline Collagen alpha-1(V) chain & P20908 & 4.26 & + & \\
\hline Complement factor $\mathrm{H}$ & P08603 & 4.57 & & + \\
\hline Inter-alpha-trypsin inhibitor heavy chain $\mathrm{H} 4$ & Q14624 & 4.61 & & + \\
\hline Complement C5 & P01031 & 4.74 & & + \\
\hline Collagen alpha-1(I) chain & P02452 & 4.84 & + & \\
\hline Ceruloplasmin & P00450 & 5.01 & & + \\
\hline Histidine-rich glycoprotein & P04196 & 5.11 & & + \\
\hline Target of Nesh-SH3 & Q7Z7G0 & 5.25 & & + \\
\hline Plasma protease $\mathrm{C} 1$ inhibitor & P05155 & 5.30 & & + \\
\hline Apolipoprotein M & 095445 & 5.65 & & + \\
\hline Inter-alpha-trypsin inhibitor heavy chain $\mathrm{H} 2$ & P19823 & 5.70 & & + \\
\hline Periostin & Q15063 & 5.81 & + & \\
\hline Apolipoprotein C-III & P02656 & 5.92 & & + \\
\hline Kinectin & Q86UP2 & 6.02 & & + \\
\hline Carboxypeptidase N subunit 2 & P22792 & 7.73 & & + \\
\hline Serum paraoxonase/arylesterase 1 & P27169 & 8.02 & & + \\
\hline Apolipoprotein L1 & 014791 & 8.95 & & + \\
\hline Ig mu chain $\mathrm{C}$ region & P01871 & 13.30 & & + \\
\hline Apolipoprotein E & P02649 & 13.80 & & + \\
\hline Inter-alpha-trypsin inhibitor heavy chain $\mathrm{H} 1$ & P19827 & 15.56 & & + \\
\hline
\end{tabular}

Footnote: Differential abundance was denoted by greater than or equal to \pm 2.0 -fold change; $p \leq 0.05$; protein identified by at least two unique peptides. Positive numbers denote higher abundance at stage II compared with stage I of autologous chondrocyte implantation (ACI). Proteins were identified using either protein dynamic compression coupled with label free quantitation LC-MS/MS or no protein dynamic compression with isobaric tags for absolute and relative quantitation (iTRAQ) LC-MS/MS. Proteins identified by both proteomic techniques are underlined and in italics

$\left.1.22 \times 10^{-6}\right)$. Further, analysis of upstream regulators to these dysregulated proteins included those identified using the LF LC-MS/MS analysis data alone, such as transforming growth factor- $\beta 1\left(p=2.05 \times 10^{-13}\right)$, dihydrotestosterone $\left(p=4.48 \times 10^{-11}\right)$ and peroxisome proliferator-activated receptor- $\alpha\left(p=1.09 \times 10^{-9}\right)$ [3].

The combined datasets were then used to generate unbiased interactome networks that represent the differentially abundant proteins (non-inferred networks), their likely interacting proteins (inferred networks) and how these proteins interact with one another, resulting in models of systemic protein response to cartilage harvest in either the responders or non-responders to ACI. Based on proteins that were differentially abundant between stages I and II of ACI in non-responders, an interactome network consisting of 115 nodes (proteins) and 40 edges (protein-protein interactions) was generated. Further, an inferred network consisting of 2893 proteins and 35,576 protein-protein interactions was generated on the basis of the addition of proteins that are likely to 


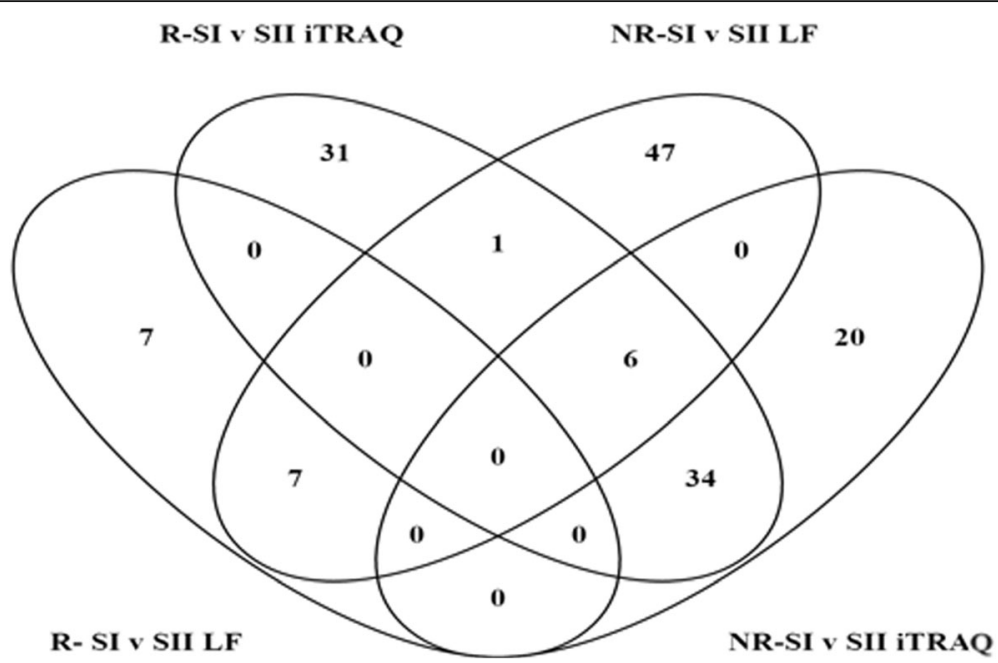

Fig. 2 Venn diagrams representing the proteins identified using isobaric tags for relative and absolute quantitation (iTRAQ) proteomics and labelfree quantitation (LF) proteomics. The proteins shown were differentially abundant ( $\geq 2.0$-fold change; $p \leq 0.05)$ in the SF at stage I (SI) compared with stage II (SII) in responders (R) compared with non-responders (NR) to ACl

interact with the differentially abundant proteins (PINA4MS interactome database). Proteins that were differentially abundant in response to cartilage harvest in responders to $\mathrm{ACI}$ were used to generate interactome networks (non-inferred, 83 nodes and 118 edges; inferred, 2084 nodes and 54,007 edges). The ModuLand algorithm was applied to each of these networks to identify modules within the network that can be hierarchically ranked to identify groups of proteins that are the most fundamental in the functioning of the network. Figure 4 highlights the top ten modules from each of the networks generated. These modules again highlight the disparity between the ACI responder and non-responder response to cartilage harvest, with only modules centred on the proto-oncogene tyrosine-protein kinase (Src) protein being identified in the inferred networks of both non-responder and responder groups. Interestingly, assessment of the functional pathways related to the ModuLand identified modules in the non-responder networks again highlighted regulation of the complement cascade $\left(p=1.68 \times 10^{-8}\right.$ by Fisher's exact test), thus providing confidence in its importance based on identification via two independent bioinformatics approaches.

\section{Discussion}

On the basis of its recent technology appraisal of ACI, NICE has recommended this treatment for a specific subset of patients with cartilage injury in the knee [2]. The identification of novel biomarkers that can strengthen current patient demographic risk factors in predicting clinical outcomes [9], as well as development of a greater understanding of the underlying biology associated with success and failure, will be beneficial, particularly because this treatment option is likely to be implemented on a wider scale in the near future. The present study builds upon our previously published work $[3,8]$, highlighting a number of novel protein candidates that have potential as biomarkers to predict ACI outcome. Moreover, comprehensive proteomic profiling of SF has further highlighted proteomic differences between responders and non-responders to ACI.

In the majority of studies in which the SF proteome has been profiled, either high-abundance proteins [11-16] or low-abundance proteins [17-22] have been assessed via depletion or non-depletion of abundant proteins prior to proteomic analysis. Our study highlights that the use of both a proteomic dynamic range compression technique (ProteoMiner ${ }^{\mathrm{rn}}$ ) [3] in tandem with analysis of non-depleted SF samples can provide a more holistic overview of proteomic changes, because both iTRAQ nLC-MS/MS and LF LC-MS/MS highlighted large numbers of differentially abundant proteins between stages I and II of ACI, with little crossover between techniques. This type of allinclusive approach to unbiased whole-proteome analysis of biological fluids may therefore be more successful in the identification of candidate biomarkers for treatments/disease states beyond those we investigated.

A limitation of our previous study [3] was that very few proteins were identified as differentially abundant between responders and non-responders at baseline. In order for biomarkers aimed at predicting ACI success to be most clinically useful, patients who are likely to fail or respond to this procedure need to be identified prior to any surgical intervention. Interestingly, analysis of non-dynamic range compressed proteins with iTRAQ 


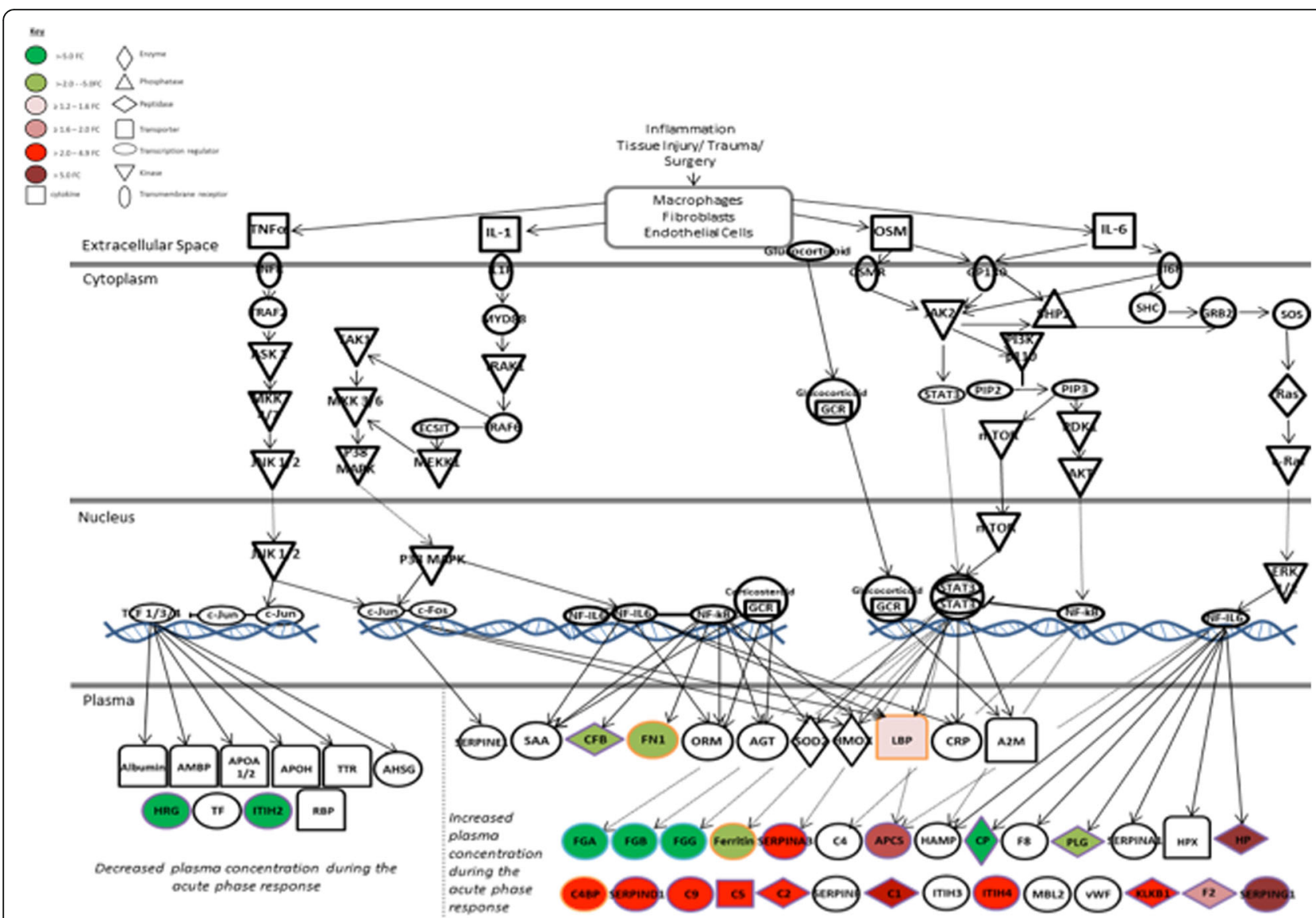

Fig. 3 Proteins of acute-phase signalling at stage II compared with stage I in non-responders to autologous chondrocyte implantation (ACI). Several synovial fluid proteins that are downstream of acute-phase response signalling were differentially abundant between stages I and II of ACl. Proteins edged in purple, orange and blue were identified using isobaric tagging for relative and absolute quantitation (iTRAQ) nano LC-MS/MS, label-free quantitation (LF) LC-MS/MS or both techniques, respectively. (Adapted from Ingenuity Pathway Analysis.)

nLC-MS/MS analysis was able to detect a greater number of differentially abundant proteins between responders and non-responders prior to stage I surgery. The protein with most altered abundance in responders compared with non-responders at stage I was C1s. This higher abundance in responders was confirmed in individual patient samples using a biochemical assay. C1s is a major constituent of the trimeric complement $\mathrm{C} 1$ protein, which triggers the classical complement pathway. Once activated, the classical complement pathway promotes inflammation to enable the removal of damaged cells and/or microbes. Moreover, $\mathrm{C} 1 \mathrm{~s}$ has been shown to cleave insulin-like growth factor 1 (IGF-1) [45] and insulin-like growth factor binding protein 5 (IGFBP-5) [46]. Both IGF-1 and IGFBP-5 are chondroprotective when in their intact state $[45,47]$, and inhibition of C1s activity within the canine SF reduced cleavage of IGFBP5 and IGF-1, resulting in reduced cartilage damage following anterior cruciate ligament rupture [45]. These studies indicate that high $\mathrm{C} 1 \mathrm{~s}$ activity levels are likely detrimental to cartilage repair. Further, the complement cascade is known to be important in the pathogenesis of $\mathrm{OA}$, with patients with $\mathrm{OA}$ demonstrating increased gene expression of complement agonists compared to inhibitors [48]. OA-related pathogenesis, such as the release of cartilage extracellular matrix molecules and the production of inflammatory mediators, induces complement activation [48]. The increased pre-operative levels that we identified in individuals who responded well to ACI perhaps indicate that ACI has potential to be successful in individuals who may have developed an early OA phenotype.

Analysis of the iTRAQ nLC-MS/MS and LF LC-MS/ MS datasets, both independently and when combined, highlighted that there is a marked proteomic shift in response to cartilage harvest (i.e., between stages I and II of ACI). This analysis resulted in a plethora of candidate biomarkers that may have the potential to be informative regarding whether an individual is likely to respond well to ACI prior to chondrocytes being implanted during stage II. The proteoglycan, collagens II-, IX- and Xdegrading enzyme, MMP3 [49] has been biochemically 


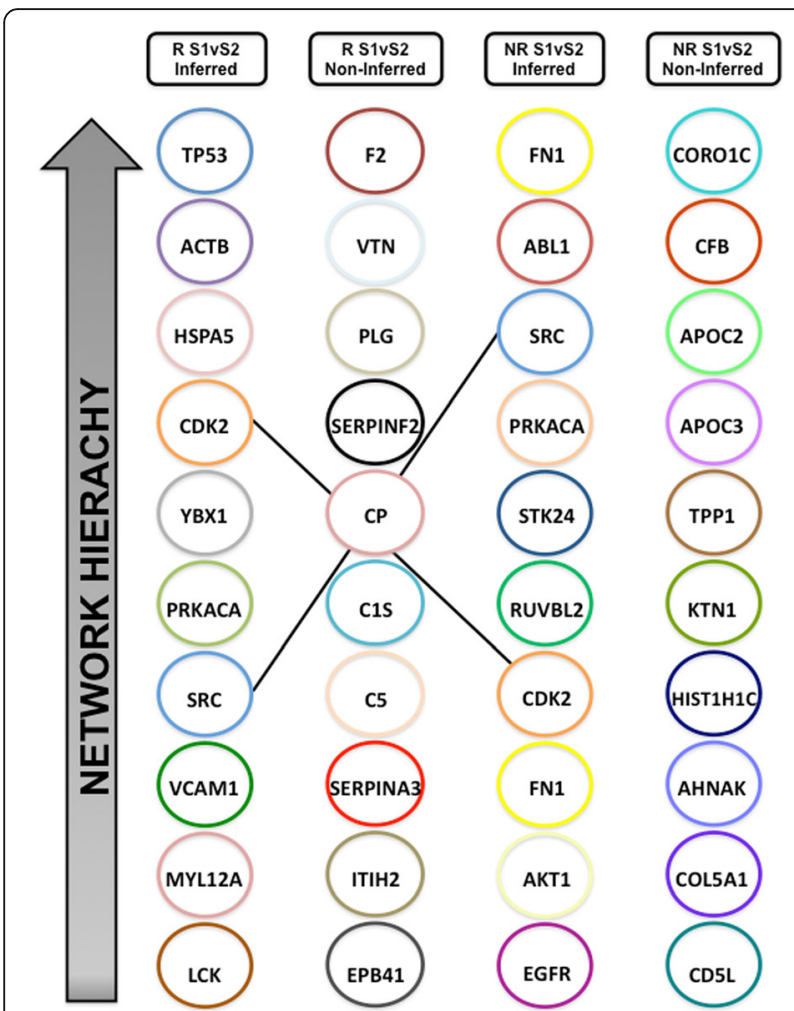

Fig. 4 The ModuLand algorithm was applied in Cytoscape to inferred and non-inferred interactome networks of differentially abundant proteins ( \pm 1 .2-fold change; $p \leq 0.05$ ) between stages I and II of autologous chondrocyte implantation in clinical responders and non-responders. Modules were identified from both non-inferred (protein changes identified from proteomic analysis only) and inferred (identified protein changes and inferred proteins interactions) networks and are ranked on the basis of their hierarchical network connectivity

validated as one of these candidate proteins that is significantly increased at stage II compared with stage I only in non-responders to ACI. Use of these biomarkers could have the potential to prevent the burden of a second surgery in a patient for whom this therapy is likely to be unsuccessful and could indicate that a greater period of time should be left from when the cartilage harvest procedure takes place to when the cells are implanted or that a tailored cartilage implantation procedure would be more efficacious.

To investigate the significant proteome shift that exists in response to cartilage harvest, pathway analyses were performed to better distinguish the underlying biological mechanisms that dictate whether an individual will respond to ACI. The acute-phase response was the pathway predicted to be most significantly differentially regulated in response to cartilage harvest in nonresponders to ACI. In-depth assessment of individual protein changes within this pathway again highlighted the benefit of using independent proteomic techniques to profile the SF, because a large number of proteins were differentially abundant between stages I and II, only three of which were identified using both techniques. The acute-phase response is the body's first systemic response to immunological stress, trauma and surgery [50]. At the site of injury/trauma, proinflammatory cytokines are normally released, activating inflammatory cells and ultimately resulting in inflammatory mediators and cytokines being released into the extracellular fluid compartment to be circulated in the blood [50]. Interestingly, previous bioinformatics analyses of the proteome of patients with late OA compared with healthy control subjects highlighted a dysregulated acute-phase response in the end-stage OA cohort [18]. The exacerbated activation of the acute-phase response in non-responders following initial surgery could indicate that these patients have a greater immune response to surgery and that they have a lesser ability to dampen the acute-phase following surgery or that they have already developed an advanced OA phenotype, deeming a therapy to repair cartilage injury unsuitable.

Finally, the datasets of combined iTRAQ nLC-MS/MS and LF LC-MS/MS identified proteins were used to generate interactome models that represent the systemic proteomic response to cartilage harvest which exists within the SF of both ACI responders and nonresponders, from which biological functional pathways could be further studied. Biological functional pathways that were identified using this approach, as well as using Ingenuity Pathway Analysis can most confidently be taken forward as candidates for further study because they have been identified by independent bioinformatic methods. Furthermore, given the complexity of the knee joint environment, it is likely that the responder/non-responder phenotype is the result of many subtle protein changes which together contribute to overall dysfunction of a biological network, rather than being the result of an individual biological molecule or pathway per se. Therefore, the interactome models generated in this study provide an important opportunity to consider how these proteins interact with one another and result in such phenotypes, and they also provide a platform for further studies to investigate how potential modifications to the ACI procedure (e.g., using co-incidental antiinflammatory drugs in non-responders at stage II) may alter these biological networks. Thus, these models may provide a potential in silico tool for predicting ACI outcome, as is commonly used in drug development strategies [51].

\section{Conclusions}

This study highlights the advantage of using two independent proteomic techniques to profile a holistic overview of the SF proteome, ideal for unbiased identification of biomarker candidates. iTRAQ nLC-MS/MS 
analysis of SF samples from individuals who have either responded well or very poorly to $\mathrm{ACI}$ has highlighted proteins that, with further validation, have the potential to predict clinical outcome prior to treatment. We have confirmed that there is a marked SF proteome shift following cartilage injury, which is exacerbated in nonresponders. Network and pathway analyses have demonstrated the complexity of the biological response underlying this proteome shift in non-responders, with several biological pathways identified that may act as targets for therapeutic intervention.

\section{Additional file}

Additional file 1: Table S1. Canonical pathways altered in the synovial fluid of clinical nonresponders at stage I compared with stage II of $\mathrm{ACl}$, identified using Ingenuity Pathway Analysis based on proteins that were identified using iTRAQ proteomics ( $\geq 1$.2-fold change). Significance was assessed using a right-sided Fisher's exact test; therefore, the most significant canonical pathways represent those that are the least likely to have been identified because of molecules being in the canonical pathway by random chance. The $z$-score represents canonical pathways that are likely activated or inhibited (based on the pattern of differentially abundant proteins); NaN means no prediction could be made based on the number of differentially abundant proteins in the pathway. Table S2. Canonical pathways altered in the synovial fluid of clinical responders at stage I compared with stage II of $\mathrm{ACl}$, identified using Ingenuity Pathway Analysis, based on proteins which were identified using iTRAQ proteomics ( $\geq 1.2$-fold change). Significance was assessed using a right-sided Fisher's exact test; therefore, the most significant canonical pathways represent those that are the least likely to have been identified because of molecules being in the canonical pathway by random chance. The z-score represents canonical pathways that are likely activated or inhibited (based on the pattern of differentially abundant proteins); NaN means no prediction could be made based on the number of differentially abundant proteins in the pathway. (XLSX $19 \mathrm{~kb}$ )

\section{Abbreviations}

ACl: Autologous chondrocyte implantation; BMl: Body mass index; C1s: Complement C1S subcomponent; ELISA: Enzyme-linked immunosorbent assay; FC: Fold change; IGF-1: Insulin-like growth factor 1; IGFBP-5: Insulin-like growth factor-binding protein 5; iTRAQ: Isobaric tagging for relative and absolute quantitation; LF: Label-free quantitation; LFC: Lateral femoral condyle; LTP: Lateral tibial plateau; MFC: Medial femoral condyle; MMP3: Matrix metalloproteinase 3; NICE: National Institute for Health and Care Excellence; nLC-MS/MS: Nano LC-MS/MS; OA: Osteoarthritis; PINA4MS: Protein Interaction Network Analysis For Multiple Sets; SCX: Strong cation exchange chromatography; SF: Synovial fluid; Src: Proto-oncogene tyrosine-protein kinase protein

\section{Acknowledgements}

We thank Professor Rob Beynon for his advice on study design and help with analysis of samples using label-free quantitation proteomic analysis.

\section{Funding}

We thank Arthritis Research UK for supporting this work via grants 19429, 20815 and 21122. The sponsors had no involvement in the study design, data collection and interpretation, or preparation of the manuscript. MJP is supported through a Wellcome Trust Clinical Intermediate Fellowship. This work was supported by Wellcome Trust grant 094476/Z/10/Z, which funded the purchase of the TripleTOF 5600 mass spectrometer at the Biomedical Sciences Research Complex Mass Spectrometry and Proteomics Facility, University of St. Andrews (Fife, UK).

\section{Availability of data and materials}

Proteomic data derived from this study have been deposited in the PRoteomics IDEntifications (PRIDE) ProteomeXchange and can be accessed using the identifier [PXD008321].

\section{Authors' contributions}

$\mathrm{CHH}$, ELW, KTW, HRF, MJP and SR conceived of and designed the study. $\mathrm{CHH}$, ELW, HRF, SLS and CHB collected data. CHH, ELW, KTW, MJP and HRF analysed and interpreted data. CHH, ELW, HRF, SR, MJP, SLS, CHB, JBR, PG and KTW drafted and critically revised the manuscript and approved the final article. PG and JBR provided patients' synovial fluid samples. KTW and SR obtained funding for the study. All authors read and approved the final manuscript.

\section{Ethics approval and consent to participate}

SF samples from patients undergoing $\mathrm{ACl}$ were collected under three independent ethical approvals: Investigating the potential for cells and molecules isolated from orthopaedic patients for modelling and understanding pathogenic conditions and developing diagnostic markers and therapies for musculoskeletal disorders and spinal cord injury (National Research Ethics Service [NRES] committee North West - Liverpool East 11/ NW/0875), Autologous cell therapy for Osteoarthritis: An evaluation of the safety and efficacy of autologous transplantation of articular chondrocytes and/or bone marrow derived stromal cells to repair chondral/osteochondral lesions of the knee (NRES committee West Midlands - Coventry and Warwickshire 11/WM/0175), and Arthritis and cartilage repair study (Shropshire and Staffordshire-Shropshire local research ethics committee 06/Q6201/9). All patients gave valid informed consent prior to their samples' being collected

\section{Consent for publication}

Not applicable for this study.

\section{Competing interests}

The authors declare that they have no competing interests.

\section{Publisher's Note}

Springer Nature remains neutral with regard to jurisdictional claims in published maps and institutional affiliations.

\section{Author details}

${ }^{1}$ Institute of Science and Technology in Medicine, Keele University, Keele, Staffordshire ST5 5BG, UK. ${ }^{2}$ Robert Jones and Agnes Hunt Orthopaedic Hospital, Oswestry, Shropshire SY10 7AG, UK. ${ }^{3}$ Chester Medical School, Chester University, Chester CH1 4BJ, UK. ${ }^{4}$ Institute of Ageing and Chronic Disease, University of Liverpool, Liverpool L7 8TX, UK. ${ }^{5}$ BSRC Mass Spectrometry and Proteomics Facility, University of St Andrews, North Haugh, Fife KY16 9ST, UK.

Received: 12 December 2017 Accepted: 21 March 2018

Published online: 02 May 2018

\section{References}

1. Kraus VB, Blanco FJ, Englund M, Henrotin Y, Lohmander LS, Losina E, et al. OARSI Clinical Trials Recommendations: soluble biomarker assessments in clinical trials in osteoarthritis. Osteoarthritis Cartilage. 2015;23(5):686-97.

2. National Institute for Health and Care Excellence (NICE). Autologous chondrocyte implantation for treating symptomatic articular cartilage defects of the knee. Technology appraisal guidance [TA477]. 4 Oct 2017. https://www.nice.org.uk/guidance/ta477/resources/autologous-chondrocyteimplantation-for-treating-symptomatic-articular-cartilage-defects-of-theknee-pdf-82604971061701. Accessed 25 Nov 2017.

3. Hulme CH, Wilson EL, Peffers MJ, Roberts S, Simpson DM, Richardson JB, et al. Autologous chondrocyte implantation-derived synovial fluids display distinct responder and non-responder profiles. Arthritis Res Ther. 2017;19:150.

4. Gillogly SD, Voight M, Blackburn T. Treatment of articular cartilage defects of the knee with autologous chondrocyte implantation. J Orthop Sport Phys Ther. 1998;28(4):241-51.

5. Richardson JB, Caterson B, Evans EH, Ashton BA, Roberts S. Repair of human articular cartilage after implantation of autologous chondrocytes. J Bone Joint Surg Br. 1999;81(6):1064-8. 
6. Wright KT, Mennan C, Fox H, Richardson JB, Banerjee R, Roberts S. Characterization of the cells in repair tissue following autologous chondrocyte implantation in mankind: a novel report of two cases. Regen Med. 2013;8:699-709.

7. Bhosale AM, Kuiper JH, Johnson WE, Harrison PE, Richardson JB. Midterm to long-term longitudinal outcome of autologous chondrocyte implantation in the knee joint: a multilevel analysis. Am J Sports Med. 2009;37(Suppl 1):131S-8S.

8. Wright KT, Kuiper JH, Richardson JB, Gallacher P, Roberts S. The absence of detectable ADAMTS-4 (aggrecanase-1) activity in synovial fluid is a predictive indicator of autologous chondrocyte implantation success. Am J Sports Med. 2017:45(8):1806-14

9. Dugard MN, Kuiper JH, Parker J, Roberts S, Robinson E, Harrison P, et al. Development of a tool to predict outcome of autologous chondrocyte implantation. Cartilage. 2017;8:119-30

10. Hsueh MF, Önnerfjord P, Kraus VB. Biomarkers and proteomic analysis of osteoarthritis. Matrix Biol. 2014;39:56-66.

11. Chiaradia E, Pepe M, Tartaglia M, Scoppetta F, D'Ambrosio C, Renzone G, et al. Gambling on putative biomarkers of osteoarthritis and osteochondrosis by equine synovial fluid proteomics. J Proteomics. 2012;75:4478-93.

12. Pan $X$, Huang $L$, Chen J, Dai $Y$, Chen X. Analysis of synovial fluid in knee joint of osteoarthritis: 5 proteome patterns of joint inflammation based on matrix-assisted laser desorption/ionization time-of-flight mass spectrometry. Int Orthop. 2012;36(1):57-64.

13. Sohn DH, Sokolove J, Sharpe O, Erhart JC, Chandra PE, Lahey LJ, et al. Plasma proteins present in osteoarthritic synovial fluid can stimulate production via Toll-like receptor 4. Arthritis Res Ther. 2012;14(1):R7.

14. Liao W, Li Z, Wang H, Wang J, Fu Y, Bai X. Proteomic analysis of synovial fluid: insight into the pathogenesis of knee osteoarthritis. Int Orthop. 2013;37(6):1045-53.

15. Noh R, Park SG, Ju JH, Chi SW, Kim S, Lee CK, et al. Comparative proteomic analyses of synovial fluids and serums from rheumatoid arthritis patients. J Microbiol Biotechnol. 2014;24(1):119-26.

16. Liao W, Li Z, Zhang H, Li J, Wang K, Yang Y. Proteomic analysis of synovial fluid as an analytical tool to detect candidate biomarkers for knee osteoarthritis. Int J Clin Exp Pathol. 2015;8(9):9975-89.

17. Mateos J, Lourido L, Fernández-Puente P, Calamia V, Fernández-López C, Oreiro N, Ruiz-Romero C, Blanco FJ. Differential protein profiling of synovial fluid from rheumatoid arthritis and osteoarthritis patients using LC-MALDI TOF/TOF. J Proteomics. 2012;75(10):2869-78.

18. Ritter SY, Subbaiah R, Bebek G, Crish J, Scanzello CR, Krastins B, et al. Proteomic analysis of synovial fluid from the osteoarthritic knee: comparison with transcriptome analyses of joint tissues. Arthritis Rheum. 2013;65(4):981-92.

19. Balakrishnan L, Nirujogi RS, Ahmad S, Bhattacharjee M, Manda SS, Renuse S, et al. Proteomic analysis of human osteoarthritis synovial fluid. Clin Proteomics. 2014;11(1):6.

20. Balakrishnan L, Bhattacharjee M, Ahmad S, Nirujogi RS, Renuse S, Subbannayya $Y$, et al. Differential proteomic analysis of synovial fluid from rheumatoid arthritis and osteoarthritis patients. Clin Proteomics. 2014;11(1):1.

21. Bennike T, Ayturk U, Haslauer CM, Froehlich JW, Proffen BL, Barnaby O, et al. A normative study of the synovial fluid proteome from healthy porcine knee joints. J Proteome Res. 2014;13(10):4377-87.

22. Bhattacharjee M, Balakrishnan L, Renuse S, Advani J, Goel R, Sathe G, et al. Synovial fluid proteome in rheumatoid arthritis. Clin Proteomics. 2016;13:12.

23. Wu WW, Wang G, Baek SJ, Shen RF. Comparative study of three proteomic quantitative methods, DIGE, CICAT, and iTRAQ, using 2D gel- or LC-MALDI TOF/TOF. J Proteome Res. 2006:5(3):651-8.

24. Bantscheff M, Schirle M, Sweetman G, Rick J, Kuster B. Quantitative mass spectrometry in proteomics: a critical review. Anal Bioanal Chem. 2007; 389(4):1017-31.

25. Lilley KS, Beynon RJ, Eyers CE, Hubbard SJ. Focus of quantitative proteomics. Proteomics. 2015;15(18):3101-3.

26. Herr MM, Fries KM, Upton LG, Edsberg LE. Potential biomarkers of temporomandibular joint disorders. J Oral Maxillofac Surg. 2011;69(1):41-7.

27. Roberts S, Evans H, Wright K, van Niekerk L, Caterson B, Richardson JB, et al. ADAMTS-4 activity in synovial fluid as a biomarker of inflammation and effusion. Osteoarthritis Cartilage. 2015;23(9):1622-6.

28. Kraus VB, Stabler TV, Kong SY, Varju G, McDaniel G. Measurement of synovia fluid volume using urea. Osteoarthritis Cartilage. 2007;15(10):1217-20.

29. Ehrich E, Davies G, Watson D, Bolohnese J, Seidenberg B, Bellamy N. Minimal perceptible clinical improvement with the Western Ontario and McMaster Universities Osteoarthritis Index questionnaire and global assessments in patients with osteoarthritis. J Rheumatol. 2000;27(11):2635-41.
30. Roos E, Lohmander L. The Knee Injury and Osteoarthritis Outcome Score (KOOS): from joint injury to osteoarthritis. Health Qual Life Outcomes. 2003:1:64.

31. Saris D, Vanlauwe J, Victor J, Almqvist K, Verdonk R, Bellemans J, et al. Treatment of symptomatic cartilage defects in the knee: characterized chondrocyte implantation results in better clinical outcome at 36 months in a randomized trial compared to microfracture. Am J Sports Med. 2009; 37(Suppl 1):10S-9S.

32. Smith HJ, Richardson JB, Tennant A. Modification and validation of the Lysholm Knee Scale to assess articular cartilage damage. Osteoarthritis Cartilage. 2009;17:53-8.

33. Lysholm J, Gillquist J. Evaluation of knee ligament surgery results with special emphasis on use of a scoring scale. Am J Sports Med. 1982;10(3):150-4.

34. Stoscheck CM. Protein assay sensitive at nanogram levels. Anal Biochem. 1987; 160(2):301-5

35. Fuller HR, Mandefro B, Shirran SL, Gross AR, Kaus A, Botting $\mathrm{CH}$, et al. Spinal muscular atrophy patient iPSC-derived motor neurons have reduced expression of proteins important in neuronal development. Front Cell Neurosci. 2016;9:506

36. Fuller H, Slade R, Jovanov-Milošević N, Babić M, Sedmak G, Šimić G, et al. Stathmin is enriched in the developing corticospinal tract. Mol Cell Neurosci. 2015;69:12-21.

37. Oliveros JC. VENNY: an interactive tool for comparing lists with Venn diagrams. 2007. http://bioinfogp.cnb.csic.es/tools/venny/. Accessed 28 Sept 2017.

38. Albert R, Barabasi AL. Statistical mechanics of complex networks. Rev Mod Phys. 2002;74(1):47-97.

39. Vidal M, Cusick ME, Barabási AL. Interactome networks and human disease. Cell. 2011;144(6):986-98

40. Cowley MJ, Pinese M, Kassahn KS, Waddell N, Pearson JV, Grimmond SM, et al. PINA v2.0: mining interactome modules. Nucleic Acids Res. 2012;40(Database issue):D862-5.

41. Barabási AL, Gulbahce N, Loscalzo J. Network medicine: a network-based approach to human disease. Nat Rev Genet. 2011;12(1):56-68.

42. Nepusz T, Yu H, Paccanaro A. Detecting overlapping protein complexes in protein-protein interaction networks. Nat Methods. 2012;9:471-2.

43. Vastrik I, D'Eustachio P, Schmidt E, Gopinath G, Croft D, de Bono B, et al. Reactome: a curated knowledge base of biologic pathways and processes. Genome Biol. 2008:8:R39.

44. Croft D, Mundo AF, Haw R, Milacic M, Weiser J, Wu G, et al. The Reactome pathway knowledgebase. Nucleic Acids Res. 2014;42(Database issue):D472-7.

45. Clemmons DR, Busby WH, Garmong A, Schultz DR, Howell DS, Altman RD, et al. Inhibition of insulin-like growth factor binding protein 5 proteolysis in articular cartilage and joint fluid results in enhanced concentrations of insulin-like growth factor 1 and is associated with improved osteoarthritis. Arthritis Rheum. 2002:46(3):694-703.

46. Busby WH, Yocum SA, Rowland M, Kellner D, Lazerwith S, Sverdrup F, et al. Complement 1s is the serine protease that cleaves IGFBP-5 in human osteoarthritic joint fluid. Osteoarthritis Cartilage. 2009;17(4):547-55.

47. van Osch GJVM, van den Berg WB, Hunziker EB, Hauselmann HJ. Differential effects of IGF-1 and TGF $\beta$-2 on the assembly of proteoglycans in pericellular and territorial matrix by cultured bovine articular chondrocytes. Osteoarthritis Cartilage. 1998;6:187-95.

48. Wang Q, Rozelle AL, Lepus CM, Scanzello CR, Song JJ, Larsen DM, et al. Identification of a central role for complement in osteoarthritis. Nat Med. 2012;17(12):1674-9.

49. Murphy G. Matrix metalloproteinases and their inhibitors. Acta Orthop Scand Suppl. 1995;266:55-60

50. Gruys E, Toussaint MJM, Niewold TA, Koopmans SJ. Acute phase reaction and acute phase proteins. J Zheihang Univ Sci B. 2005;6(11):1045-56.

51. Guney E, Menchem J, Vidal M, Barabasi AL. Network-based in silico drug efficacy screening. Nat Commun. 2016;7:10331. 